\title{
Thermodynamic Model of Wear Intensity of Cutting Tools With Coatings
}

\author{
Sergey Grigoriev ${ }^{1, *}$, Mars Migranov ${ }^{1}$, Artur Migranov ${ }^{1}$, Abdumalik Seitkulov² $^{2}$ \\ ${ }^{1}$ Moscow State Technological University "STANKIN", RU-127055, Moscow, Russian Federation \\ ${ }^{2}$ Kazakh National Technical University, KZ-050013, Almaty, Republic of Kazakhstan
}

\begin{abstract}
On the basis of thermodynamics of nonequilibrium processes the model is developed, allowing to predict wear resistance and others tribotechnical parametres hardloaded high-temperature interfaces. For the predicted adaptation of friction surfaces and a decrease in the wear rate, it is necessary to use tool materials and wear-resistant coatings containing chemical elements and compounds capable, under certain conditions, of chemically interacting with the material being processed and with the environment, creating non-equilibrium secondary structures with negative entropy production. Contributions of additional impacts on the cutting zone due to the use of coolant, unsteadiness of the cutting mode elements, and other relevant factors should also be considered.
\end{abstract}

\section{Introduction}

It is well known [1, 2] that the main phenomena during friction are concentrated in a thin near-surface layer. The thermodynamic aspects of the state of this layer and the relationship of wear with this state are of scientific and practical interest. It was convincingly shown in [3] that any tribosystem should be considered as an open nonequilibrium thermodynamic system. In works $[4,5$, $6]$, the principle of secondary dissipative heterogeneity is formulated, according to which, in the process of friction, phenomena of structural adaptability (adaptation) of contacting materials occur, in which all types of interaction of bodies are localized in a thin-film object - secondary structures (SS).

In accordance with this principle, secondary structures are necessary for the dissipation of energy during its transition from the friction zone to the rubbing bodies, and the dissipation of energy should occur with the lowest rate of entropy growth. Secondary structures perform protective functions, limiting the spread of interaction inside rubbing bodies and reducing the intensity of this interaction, therefore their appearance corresponds to the Le Chatelier principle $[3,5]$.

\section{Theoretical and experimental hypothesis}

It is known [7] that the change in entropy of any thermodynamic system is equal to

$$
\mathrm{dS}=\mathrm{d}_{\mathrm{e}} \mathrm{S}+\mathrm{d}_{\mathrm{i}} \mathrm{S},
$$

where $d_{e} S$ is the change in entropy due to the exchange of matter and energy with the external environment; $\mathrm{d}_{\mathrm{i}} \mathrm{S}$ - change in entropy due to "uncompensated transformation", i.e. this entropy is produced by irreversible processes within the system.

In an equilibrium stationary state, the change in entropy over time $t$ is equal to zero, i.e.

$$
\frac{d S}{d t}=\frac{d_{i} S}{d t}+\frac{d_{e} S}{d t}=0
$$

and thus $\frac{d_{i} S}{d t}>0$, then $\frac{d_{e} S}{d t}<0$

In the thermodynamics of irreversible processes, an important role is played by the dissipative component $\frac{d_{i} S}{d t}$, which describes the production of entropy due to internal sources in the system

$$
\frac{d_{i} S}{d t}=\sum J_{k} \cdot X_{k}
$$

where $X_{k}$ is the generalized force; $J_{k}$ is the generalized flow caused by it [7, 8].

When developing the principles of rational choice and application of wear-resistant tool materials, let us consider the tribosystem "tool - work material". The following main thermodynamic flows pass through the secondary structures of this tribosystem: heat flow, matter flow, flow of physicochemical transformations and flow of additional influences (use of coolant, unsteadiness of cutting conditions, etc.).

Imagine a system consisting of a rubbing body and energy sources in the friction zone. We believe that energy sources do not have mass, and therefore do not have entropy.

Let us consider the change in the production of entropy of one of the contacting bodies - a cutting tool when cutting metals. First, we assume that only two 
thermodynamic flows pass through the VS of the rubbing surfaces of the tool: the heat flow and the substance flow. Then the change in the production of entropy of the aircraft with time in the system under consideration (without taking into account the relationship between flows) is:

$$
\frac{d_{i} S}{d t}=\frac{d S_{q}}{d t}+\frac{d S_{m}}{d t}
$$

Here $\frac{d S_{q}}{d t}$ - the change in the production of the entropy of the heat flow - is equal to:

$$
\frac{d S_{q}}{d t}=J_{q} \cdot X_{q}
$$

where $\mathrm{J}_{\mathrm{q}}$ is the heat flux, $\mathrm{X}_{\mathrm{q}}=(\operatorname{grad} \mathrm{T}) / \mathrm{T}^{2}$ is the thermodynamic force causing the heat flux.

( $\mathrm{T}$ - temperature), according to the Biot-Fourier law of heat transfer $\mathrm{J}_{\mathrm{q}}=-\lambda \cdot \operatorname{grad} \mathrm{T}(\lambda$ - thermal conductivity). We assume that only a certain part (X) of the mechanical frictional energy is dissipated by the heat flux, i.e.

$$
\mathrm{J}_{\mathrm{q}}=\mathrm{f}_{\mathrm{m}} \cdot \mathrm{p}_{\mathrm{r}} \cdot \mathrm{V} \cdot \mathrm{X}(\mathrm{X}<1)
$$

$\left(f_{m}\right.$ - coefficient of friction; $p_{r}$ - specific normal load; $\mathrm{V}$ - cutting-sliding speed).

Then, after the appropriate substitutions and transformations, expression (5) takes the form

$$
\frac{d S_{q}}{d t}=\frac{\left(f_{m} \cdot p_{r} \cdot V \cdot X\right)^{2}}{\lambda \cdot T^{2}} .
$$

The change in the entropy of the flow of matter in the $\mathrm{BC}$ is equal to:

$$
\frac{d S_{m}}{d t}=J_{m} \cdot X_{m}
$$

where $\mathrm{Jm}$ is the substance transfer flux; $\mathrm{Xm}$ is the thermodynamic force causing the flow of matter;

$\mathrm{Xm}=(\operatorname{grad} \mathrm{C}) / \mathrm{T}(\mathrm{C}$ is the concentration of the substance). According to Fick's law of transfer of matter; $\mathrm{Jm}=\mathrm{me}-\mathrm{D} \cdot \mathrm{grad} \mathrm{C}$ (D is the diffusion coefficient). We assume that some part $(\mathrm{Y})$ of the total production of entropy during friction is spent on the formation of the flow of matter, i.e.

$$
\mathrm{J}_{\mathrm{m}}=\mathrm{f}_{\mathrm{m}} \cdot \mathrm{p}_{\mathrm{r}} \cdot \mathrm{V} \cdot \mathrm{Y}(\mathrm{Y}<1) .
$$

Then expression (8) takes the form

$$
\frac{d S_{m}}{d t}=f_{m} \cdot p_{r} \cdot V \cdot Y \frac{m_{e}}{D \cdot T} .
$$

After substituting expressions (8), (10) into formula (4), we get:

$$
\frac{d_{i} S}{d t}=\frac{\left(f_{m} \cdot p_{r} \cdot V \cdot X\right)^{2}}{\lambda \cdot T^{2}}+f_{m} \cdot p_{r} \cdot V \cdot Y \frac{m_{e}}{D \cdot T} .
$$

According to the theorem of I. Prigogine [7, 8], the change in the production of entropy with time in the system in a stationary state is minimal and stable within certain limits of the change in parameters.

Differentiating expression (11) with respect to cutting speed V (sliding speed) - as an independent variable of the tribological system under consideration and equating the result to zero, we obtain the condition of stationarity of this system:

$$
\frac{2 \cdot f_{m}^{2} \cdot p_{r}^{2} \cdot V \cdot X^{2}}{\lambda_{c p} \cdot T}-\left|Y \frac{m_{e}}{D_{c p}}\right|=0 .
$$

The sign in front of the second term is taken negative, since from the additivity condition [7] it is proportional to the wear rate of the rubbing body material, and wear particles are removed from the tribosystem with their entropy content.

From expression (12), the flow of matter can be determined:

$$
m_{e}=\frac{2 \cdot f_{m}^{2} \cdot p_{r}^{2} \cdot V \cdot X^{2} \cdot D_{c p}}{\lambda_{c p} \cdot T \cdot Y} .
$$

In expression (13), the average values of thermal conductivity $\lambda_{\mathrm{cp}}$ and diffusion coefficient $\mathrm{D}_{\mathrm{cp}}$ in secondary structures are introduced on the assumption that they are independent of the cutting speed.

Obviously, the value of the wear rate of the cutting tool is related to the substance flow $\mathrm{m}_{\mathrm{e}}$, which is determined by the concentration gradient of the substance. And only with wear (removal of saturated layers) is it possible to continue the flow of the substance, since the gradient of its concentration appears again. Then the linear wear rate $\mathrm{J}_{\mathrm{h}}$ and the substance flow $m_{e}$ can be related by the ratio:

$$
J_{h}=\frac{k \cdot m_{e}}{\rho \cdot V},
$$

where $\mathrm{k}$ is the coefficient of proportionality; $\rho$ - substance density of worn-out particles.

The friction coefficient on the flank surface of cutting tools, as shown in [9], is mainly determined by the adhesion component of the friction coefficient and is equal to

$$
f_{m}=\frac{\tau_{n n}}{p_{r n}},
$$

where $\tau_{\mathrm{nn}}$ is the shear strength of adhesive bonds; $\mathrm{p}_{\mathrm{rn}}$ is the limiting normal stress at the plastic contact.

It is this contact that takes place on the back surface of the cutting tools, i.e. in expression (13) $\mathrm{p}_{\mathrm{r}}=\mathrm{p}_{\mathrm{rn}}$ Then expression (15) can be represented as:

$$
J_{h}=\frac{2 \cdot X^{2} \cdot k}{Y} \cdot \frac{\tau_{n n}^{2} \cdot D_{c p}}{\lambda_{c p} \cdot T \cdot \rho} \cdot
$$


From expression (16) it can be seen that the intensity of tool wear along the flank surface is largely determined by the temperature dependences $\tau_{\mathrm{nn}}(\mathrm{T})$.

Formula (16) is an analytical expression for the intensity of wear of cutting tools, which is obtained from the condition of stability of a stationary state with a minimum production of entropy at the frictional contact "tool - workpiece material".

From expression (16), it follows that under conditions when the effect of physicochemical transformations in the friction contact VS is insignificant and can be disregarded:

$$
C=\frac{J_{h} \cdot T}{\tau_{n n}^{2}}=\frac{2 \cdot X^{2} \cdot k}{Y} \cdot \frac{D_{c p}}{\lambda_{c p} \cdot \rho} .
$$

According to (17), the value of $C$ should not change with increasing temperature $\mathrm{T}$.

\section{Results and discussion}

Tables 1 - 3 present the results of experimental studies and the values of $\mathrm{C}$ calculated from these results, depending on the cutting temperature, which changes due to changes in the cutting speed. It can be seen from the tables that for each state of the tribosystem "tool workpiece material", an increase in temperature $\mathrm{T}$ in the investigated range to a certain value, called the characteristic $\mathrm{T}_{\text {xap }}$, practically does not change the value of C. This temperature in [10] is called the optimal cutting temperature, i.e. to. at this temperature, the wear rate of the cutting tool is minimal.

Table 1. Turning of KhN70VMTYUB alloy with VK6M cutter; cutting speed V = $1565 \mathrm{~m} / \mathrm{min}$; depth $\mathrm{t}=0.5 \mathrm{~mm}$; feed $\mathrm{S}=0.08 \mathrm{~mm} / \mathrm{rev}$

\begin{tabular}{|c|c|c|c|}
\hline $\begin{array}{c}\text { Temperature } \\
\text { cutting T, } \mathbf{K}\end{array}$ & $\begin{array}{c}\boldsymbol{\tau}_{\mathbf{n n}}, \\
\mathbf{M P a}\end{array}$ & $\mathbf{J}_{\mathbf{h}} \cdot \mathbf{1 0}^{\mathbf{7}}$ & $\begin{array}{c}\mathbf{C} \cdot \mathbf{1 0}^{\mathbf{1 0}}, \\
\mathbf{K} / \mathbf{( M P a})^{\mathbf{2}}\end{array}$ \\
\hline 873 & 620 & 1,1 & 2,5 \\
\hline 923 & 540 & 0,9 & 2,8 \\
\hline 973 & 500 & 0,8 & 2,9 \\
\hline 1073 & 380 & 2 & 15 \\
\hline 1173 & 220 & 4 & 96 \\
\hline
\end{tabular}

Table 2. Milling of steel 30HGSA (HRCэ 35 ... 38) singletooth end mill T15K6; cutting speed

$\mathrm{V}=40-120 \mathrm{~m} / \mathrm{min}$; depth $\mathrm{t}=0.5 \mathrm{~mm}$; feed per tooth $\mathrm{S}_{\mathrm{z}}=$ $0.1 \mathrm{~mm} / \mathrm{rev}$

\begin{tabular}{|c|c|c|c|}
\hline $\begin{array}{c}\text { Temperature } \\
\text { cutting T, K }\end{array}$ & $\begin{array}{l}\tau_{\mathrm{nn}}, \\
\mathrm{MPa}\end{array}$ & $\mathrm{J}_{\mathrm{h}} \cdot 10^{5}$ & $\begin{array}{c}\mathrm{C} \cdot 10^{8}, \\
\text { K/(MPa) }\end{array}$ \\
\hline 923 & 600 & 1,3 & 3,5 \\
\hline 993 & 350 & 0,53 & 4,2 \\
\hline 1023 & 300 & 0,45 & 4,8 \\
\hline 1053 & 280 & 1,0 & 13 \\
\hline 1093 & 210 & 1,32 & 33 \\
\hline
\end{tabular}

Table 3. Turning of KhN70VMTYUB alloy R18F2K8M cutter; cutting speed $\mathrm{V}=3-10 \mathrm{~m} / \mathrm{min}$; depth $\mathrm{t}=0.5 \mathrm{~mm}$; feed $\mathrm{S}=0.12 \mathrm{~mm} / \mathrm{rev}$

\begin{tabular}{|c|c|c|c|}
\hline $\begin{array}{c}\text { Temperature } \\
\text { cutting T, K }\end{array}$ & $\begin{array}{c}\tau_{\mathrm{nn}}, \\
\text { MPa }\end{array}$ & $\mathbf{J}_{h} \cdot 10^{7}$ & $\begin{array}{c}\mathrm{C} \cdot \mathbf{1 0}^{10}, \\
\mathrm{~K} /(\mathbf{M P a})^{2}\end{array}$ \\
\hline 593 & 780 & 1,1 & 1,1 \\
\hline 693 & 740 & 0,9 & 1,1 \\
\hline 763 & 640 & 0,7 & 1,3 \\
\hline 783 & 620 & 1,8 & 3,7 \\
\hline 813 & 600 & 4,8 & 10,8 \\
\hline
\end{tabular}

This indicates: firstly, that up to temperatures $T_{\text {xap }}$, physicochemical transformations at a frictional contact cannot play a decisive role in the formation of a material flow and wear of a tool (possibly due to the fact that these transformations are practically absent up to these temperatures) ; secondly, the correspondence of the wear intensity of cutting tools (at least up to temperatures $\mathrm{T}_{\text {xap }}$ ) to expression (16) shows that the state of the BC at the frictional contact "tool - workpiece material" can be considered as stationary with a minimum production of entropy, stable with respect to speed changes (temperature) cutting; thirdly, at temperatures $\mathrm{T}_{\text {xap }}$ and higher, obviously, new connections are established between the elements of the system (flow of matter and temperature), which can be explained by the appearance of a new structure that promotes ordering of the system.

Such results were obtained for substantially different conditions for cutting metals: turning and milling; carbide and high-speed tool materials; heat-resistant alloys and structural steels as workable materials.

It was shown in [11] that if the mechanical energy of friction is the only source of changes in the production of entropy, the thermodynamic system does not lose stability. For self-organization to be possible, more than one independent source of energy dissipation is required. They can be non-spontaneous chemical reactions initiated by friction [12,13]. Consequently, at cutting temperatures Tchar and higher, new sources of energy dissipation appear on the friction contact - nonspontaneous chemical reactions initiated by friction, with excessive production of entropy, some of which can become negative (depending on the type of chemical reactions occurring).

Then the change in the production of entropy of the air force with time in the tribosystem, taking into account the physical and chemical transformations, is equal to:

$$
\frac{d_{i} S}{d t}=\frac{d S_{q}}{d t}+\frac{d S_{m}}{d t}+\frac{d S_{\phi}}{d t}
$$

Here, the change with time of the entropy of the flow of physicochemical transformations in the air force according to [8] is:

$$
\frac{d S_{\phi}}{d t}=J_{x} \cdot X_{x}
$$

where $\mathrm{Jx}$ is the rate of chemical reactions;

$\mathrm{Xx}$ - thermodynamic force causing chemical reactions; 
$\mathrm{Xx}=\mathrm{A} / \mathrm{T}$ (A is chemical affinity). According to studies [14-17], near thermodynamic equilibrium, the rate of a chemical reaction and chemical affinity are related by the ratio:

$$
V_{x}=L_{11} \cdot R \cdot T \cdot\left(\exp \frac{A}{R \cdot T}-1\right)
$$

where $\mathrm{L}_{11}$ is the coefficient of conjugate interactions, $\mathrm{R}$ is the gas constant.

$$
\text { Expanding }\left(\exp \frac{A}{R \cdot T}\right) \text { in a series and discarding }
$$

the terms of the second and further degrees of smallness, we get:

$$
V_{x} \approx L_{11} \cdot A \cdot
$$

Let us assume that some part ( $\mathrm{Z}$ ) of the mechanical frictional energy is spent on physicochemical transformations in the VS, i.e.

$$
J_{\mathrm{x}}=\mathrm{f}_{\mathrm{m}} \cdot \mathrm{p}_{\mathrm{r}} \cdot \mathrm{V} \cdot \mathrm{Z}(\mathrm{Z}=1-\mathrm{X}-\mathrm{Y})
$$

Then expression (19) takes the form

$$
\frac{d S_{\phi}}{d t}=f_{m} \cdot p_{r} \cdot V \cdot Z \frac{V_{x}}{L_{11} \cdot T} .
$$

After substituting expressions (11) and (23) into (18), we obtain

$$
\begin{aligned}
& \frac{d_{i} S}{d t}=\frac{\left(f_{m} \cdot p_{r} \cdot V \cdot X\right)^{2}}{\lambda \cdot T^{2}}- \\
& -\left|f_{m} \cdot p_{r} \cdot V \cdot Y \frac{m_{e}}{D \cdot T}\right| \pm \\
& \pm\left|f_{m} \cdot p_{r} \cdot V \cdot Z \frac{V_{x}}{L_{11} \cdot T}\right|
\end{aligned}
$$

If, in the general case, thermodynamic flows of heat, matter, physicochemical transformations and additional influences pass in the secondary structures of the tribosystem "tool - processed material" [18-22], then the change in aircraft production over time will be equal to

$$
\begin{aligned}
& \frac{d_{i} S}{d t}=\frac{\left(f_{m} \cdot p_{r} \cdot V \cdot X\right)^{2}}{\lambda \cdot T^{2}}- \\
& -\left|f_{m} \cdot p_{r} \cdot V \cdot Y \frac{m_{e}}{D \cdot T}\right|_{ \pm} \\
& \pm\left|f_{m} \cdot p_{r} \cdot V \cdot Z \frac{V_{x}}{L_{11} \cdot T}\right|+J_{s} \cdot X_{s}
\end{aligned}
$$

where $\mathrm{J}_{\mathrm{B}}$ is the flow of additional impacts;

$\mathrm{X}_{\mathrm{B}}$ - thermodynamic force causing the flow of additional influences. Specification of the values of $J_{B}$ and $X_{B}$ depends on the type of applied additional influences. In the general case, this component of entropy production does not depend on the characteristics of friction at the frictional contact.

Therefore, for the predicted adaptation of friction surfaces and a decrease in the wear rate, it is necessary to use tool materials and wear-resistant coatings containing chemical elements and compounds capable, under certain conditions, of chemically interacting with the material being processed and with the environment, creating non-equilibrium secondary structures with negative entropy production [23-28]. Additional influences on the cutting zone (the use of coolant, unsteadiness of the cutting mode elements, etc.) should contribute to this.

Thus, the presented experimental results confirmed the passage of self-organization at cutting temperatures Txap and higher and the formation of nonequilibrium dissipative structures on the frictional contact "tool workpiece material".

\section{Acknowledgments}

This research was funded by Ministry of Science and Higher Education of the Russian Federation, Grant No. 0707-2020-0025. This work was carried out using equipment provided by the Center of Collective Use of MSUT "STANKIN".

\section{References}

1. I.V. Kragelskyю Mech. Eng., 525, (1977)

2. B.I. Kostetsky. Technics, 395, (1970)

3. L.I. Bershadsky. Knowledge, 253, (1990)

4. B.I. Kostetsky. Technics, 26, (1976)

5. I.S. Gershman. Fric. Wear. 16, 1, 61-70, (1995)

6. V.S. Ivanova. Fric. Wear. 18, 1, 74-79, (1997)

7. I. Prigogine. Inostr. lit., 127, (1960)

8. I. Prigogine. Mir, 461, (2002)

9. L.Sh. Shuster. Mashin., 96, (1988)

10. A.D. Makarov. Mech. Eng., 278, (1976)

11. I.S. Gershman. Doct. diss.VNIIZhT

12. G. Heinike. Mir. 582, (1987)

13. S.B Bulgarevich. MGTU im. N.E. Bauman, 60-67, (2005)

14. E.M. Gutman. Metallurgy, 230, (1974)

15. M.A. Volosova, S.N. Grigor'ev, V.V. Kuzin, Refract. Ind. Ceram., 55, 565, (2015)

16. M. Volosova, S. Grigoriev, A. Metel, A. Shein, Coatings, 8, 287, (2018)

17. M.A. Volosova, S.N. Grigor'ev, V.V. Kuzin, Refract. Ind .Ceram., 56, 197, (2015)

18. M.A. Volosova, S.N. Grigor'ev, V.V. Kuzin, Refract. Ind. Ceram., 55, 487, (2015)

19. V.V. Kuzin, S.N. Grigoriev, M.A. Volosova, J. Frict. Wear, 35(6), 505, (2014)

20. S.N. Grigoriev, O.V. Sobol, V.M. Beresnev, I.V. Serdyuk, A.D. Pogrebnyak, D.A. Kolesnikov, U.S. Nemchenko, J. Frict. Wear, 35(5), 359, (2014)

21. O.V. Sobol', A.A. Andreev, S.N. Grigoriev, V.A. Stolbovoy, Probl. At. Sci. Technol., 4, 174, (2011)

22. A.S. Metel, V.P. Bolbukov, M.A. Volosova, S.N. Grigoriev, Yu.A. Melnik, Instrum. Exp. Tech., 57(3), 345, (2014) 
23. S.N. Grigoriev, M.A. Volosova, A.A. Vereschaka, N.N. Sitnikov, F. Milovich, J.I. Bublikov, S.V. Fyodorov, A.E. Seleznev, Ceram. Int., 46(11), 18241, (2020)

24. V.V. Kuzin, S.N. Grigor'ev, M.A. Volosova, Refract. Ind. Ceram., 54, 376, (2014)

25. V.V. Kuzin, S.N. Grigoriev, M.A. Volosova, J. Frict. Wear, 36(1), 40, (2015)

26. P. Huang, W. Qi, X. Yin, J.O. Choi, X.C. Chen, J.S. Tian, J.X. Xu, H.C. Wu, J.B. Luo, CARBONT, 154, 203-210 (2019)

27. H.W. Chen, M. McGurr, M. Brickhouse, Proceedings of SPIE, 9472 (2015)

28. J. Zekonyte, T. Polcar, ACS APPLIED MATERIALS \& INTERFACES, 7(38), 2105621064 (2015) 